\title{
Pseudomonas aeruginosa: patogenicidad y resistencia antimicrobiana en la infección urinaria
}

\author{
Victor Manuel Paz Zarza', Simran Mangwani Mordani', Alejandra Martínez Maldonado', \\ Diego Álvarez Hernández', Solano-Gálvez Sandra Georgina² y Rosalino Vázquez-López ${ }^{1, \&}$
}

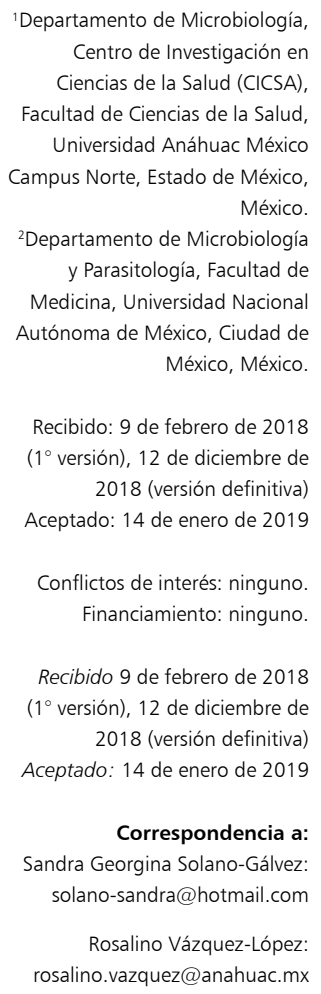

Recibido: 9 de febrero de 2018

( $1^{\circ}$ versión), 12 de diciembre de

2018 (versión definitiva)

Aceptado: 14 de enero de 2019

Conflictos de interés: ninguno. Financiamiento: ninguno.

Recibido 9 de febrero de 2018 ( $1^{\circ}$ versión), 12 de diciembre de 2018 (versión definitiva) Aceptado: 14 de enero de 2019

Correspondencia a: Sandra Georgina Solano-Gálvez: solano-sandra@hotmail.com

Rosalino Vázquez-López: rosalino.vazquez@anahuac.mx

\section{Historia y taxonomía}

$\mathrm{E}$ 1 descubrimiento del género bacteriano Pseudomonas fue descrito por primera vez a finales del siglo XIX por el profesor Walter Migula del Instituto Karlsrule en Alemania. En sus escritos describiría a este microorganismo como "Células con órganos polares. La formación de esporas ocurre en algunas especies, pero es raro" Posteriormente se descubriría que lo que el profesor nombró como "esporas" serían en realidad gránulos refráctiles de materiales de reserva. Este fue el inicio del término "Pseudomonas", presumiblemente haciendo referencia etimológicamente a unas "falsas unidades o monadas".

El término "aeruginosa" surgió del investigador Schroeter en el año de 1872. El término hacía alusión a los colores que la bacteria mostraba en ciertas condiciones de cultivo, un color similar como el cobre oxidado, como un verde-azulado. Shroeter publicó que esto era debido a un pigmento soluble en agua, del cual posteriormente se hablaría como piocianina. En su relato propuso el nombre para la bacteria recién cultivada como Bacterium aeruginosum. Más tarde, los microbiólogos sólo reconocerían una bacteria que produce piocianina por lo que este nombre quedaría en desuso ${ }^{2}$.

La especie per se Pseudomonas aeruginosa, antes denominada Bacillus pyocyaneus, fue aislada primeramente por Carle Gessard en 1882. Migula incluyó esta especie dentro de su género aportando diversos sinónimos basándose en los propuestos por Gessard y Schroeter, además, de Pseudomonas pyocyaneus y Micrococcus pyoceaneus. Finalmente, y tras varios años, se estableció que $P$. aeruginosa es la nomenclatura oficial para poder asignar a esta especie bacteriana debido a su homogeneidad fenotípica ${ }^{3}$.

El estudio taxonómico del género Pseudomonas tuvo grandes modificaciones desde el descubrimiento de la bacteria hasta un reordenamiento de especies en los últimos años. En un principio, Ferdinand Cohn agrupó a las bacterias con base en la morfología bacteriana y de las colonias en $1872^{4}$.

A lo largo de los años, esta clasificación fue cambiando a aspectos más fisiológicos, así como los factores de patogenicidad para llegar a una clasificación más precisa. Sin embargo; la definición de Pseudomonas spp. como bacterias gramnegativas, aeróbicas, que no esporulan, con motilidad por flagelos polares, no hacía diferencia significativa con otras bacterias gramnegativas. Fue entonces cuando Stanier propuso una nueva clasificación taxonómica de este género basándose en el perfil metabólico de 267 especies sobre 146 metabolitos, lo que aunado con los experimentos de identificación mediante ADN y la hibridación ADN-ADN aclararon la clasificación fenotípica ${ }^{5}$.

Finalmente, Palleroni en 1973 reporta la clasificación 
genotípica basada en la secuenciación de la subunidad $16 \mathrm{~S}$ del ARNr, en la que se analizó y dividió al género Pseudomonas en cinco subgrupos y sólo las especies más representativas del grupo 1 estarían dentro del género original, mientras que las otras terminarían siendo incluidas en otros géneros bacterianos como Burkholderia, Xanthomonas y Comamonas.

Actualmente, el género Pseudomonas pertenece a la familia Pseudomonadaceae que incluye otros géneros como Azomonas, Azotobacter, Cellvibrio, Mesophilobacter, Flavimonas and Rugamonas ${ }^{4,7}$. La familia se encuentra a su vez en el orden Pseudomonadales, en clase Gammaproteobacteria ${ }^{8}$, siendo del filo Proteobacteria y del dominio Bacteria9.

\section{Características morfológicas, químicas y relación clínica}

Pseudomonas aeruginosa es un patógeno ubicuo, oportunista y bastante persistente en el medio ambiente. Esta bacteria tiene forma de bastón aproximadamente de 0,5-1 $\mu \mathrm{m}$ in diámetro y de $1,5-5 \mu \mathrm{m}$ de largo ${ }^{4,9}$. Cuentan con un flagelo polar que le confiere la motilidad necesaria. Se considera a esta especie como bacteria aerobia facultativa debido a la capacidad que tiene para crecer en medios anaerobios tomando el nitrógeno o arginina como terminal de aceptación de protones ${ }^{8,10}$. Este patógeno ubicuo en el medio ambiente puede llegar a persistir de manera eficaz en el agua y en el suelo viviendo con un requerimiento nutricional mínimo y tolerando diversos medios físicos ${ }^{8}$. Puede crecer entre 20 y $43^{\circ} \mathrm{C}$, y al crecer en altas temperaturas se diferencia del resto de las otras especies de Pseudomonas ${ }^{11}$. Se caracteriza por ser parte del grupo de no fermentadores que tienen en común la incapacidad de fermentar lactosa, con la capacidad de utilizar fuentes de carbono y nitrógeno como acetato y amoniaco, obteniendo energía de la oxidación de azúcares ${ }^{11}$.

La bacteria también tiene la capacidad para producir una serie de proteasas (proteasa alcalina, proteasa IV) y elastasas, enzimas capaces de degradar múltiples proteínas inmunoreguladoras, incluyendo las proteínas surfactantes A y D, el complemento, inmunoglobulinas y péptidos antibacterianos. Cabe mencionar que los efectos patogénicos de $P$. aeruginosa son ampliamente estudiados en el tracto respiratorio; sin embargo, también causa infecciones corneales y queratitis (en particular debido a la proteasa alcalina y proteasa IV $)^{12}$.

Tanto las capacidades para persistir en condiciones medio ambientales adversas como los mecanismos de patogenicidad que posee, han convertido a $P$. aeruginosa en un principal microorganismo relacionado con las infecciones nosocomiales, responsable aproximadamente de 10 a $15 \%$ de las infecciones nosocomiales mundiales ${ }^{11,13}$.
Se le considera la quinta causa más frecuente en las infecciones en general a nivel mundial, la segunda causa de neumonía nosocomial, la tercera causa de infecciones urinarias, el cuarto de infecciones de sitio quirúrgico y el séptimo responsable de sepsis ${ }^{14}$. Este patógeno afecta principalmente a pacientes inmunocomprometidos como en el caso de pacientes quemados o que tienen fibrosis quística $^{15}$.

\section{Factores de patogenicidad de $P$. aeruginosa}

La capacidad que tiene $P$. aeruginosa para causar un amplio margen de infecciones radica en la gran variedad de factores de patogenicidad que posee. Estos factores se encuentran agrupados en dos variantes: Factores de patogenicidad asociados a la célula bacteriana y factores de patogenicidad secretados (Tabla 1$)^{8}$.

\section{Factores de patogenicidad asociados a la célula bacteriana}

Dentro de este tipo de factores se encuentra el flagelo que confiere motilidad a la célula y el lipopolisacárido (LPS). El flagelo de $P$. aeruginosa contiene la proteína flagelar FliD, que le confiere a la bacteria la capacidad de adherirse en la mucosa de las vías respiratorias ${ }^{8,16}$. De la misma forma, es posible que esta proteína esté involucrada en la mediación inicial de la interacción con la superficie de la vía aérea uniéndose con el glicoesfingolípido asialo M1 (aGM1) de las células epiteliales ${ }^{17}$. Pseudomonas aeruginosa también cuenta con la proteína flagelar FliC, principal factor que desencadena la secreción de péptidos antimicrobianos por el sistema inmune, liberación de trampas extracelulares mediadas por neutrófilos $\left(\mathrm{NET}^{\prime} \mathrm{s}\right)^{18}$

Tabla 1. Factores de patogenicidad de Pseudomonas aeruginosa

\begin{tabular}{|c|c|}
\hline Factores & Genes o proteínas involucradas \\
\hline $\begin{array}{l}\text { Asociados a célula bacteriana } \\
\text { Flagelo } \\
\text { Pili (Tipo IV) } \\
\text { Proteínas de membrana } \\
\text { Secretados }\end{array}$ & $\begin{array}{l}\text { FliC, Flid } \\
\text { PilA, PilB, PilT, PilU } \\
\text { LecA, LecB, LPS }\end{array}$ \\
\hline $\begin{array}{l}\text { Factores asociados a la formación de biopelícula } \\
\text { Efectores SST2 } \\
\text { Efectores SST3 } \\
\text { Efectores SST5 } \\
\text { Pigmentos } \\
\text { Efectores quorum sensing }\end{array}$ & $\begin{array}{l}\text { PelA-PelG, Psl, alginato } \\
\text { LasA, LasB } \\
\text { ExoA, ExoS, ExoT, ExoU, ExoY } \\
\text { EstA } \\
\text { Piocianina } \\
\text { LasIR, RhIIR, rhIAB, hcnABC, chic }\end{array}$ \\
\hline
\end{tabular}


y además, posee la capacidad de ser reconocida a través de los receptores tipo Toll (TLR) tipo 5 (TLR5) ${ }^{19}$ teniendo como consecuencia una expresión de IL-18 e IL-1B, lo que puede desencadenar a una muerte celular piroptótica mediante la vía de vía NFkB (factor nuclear kappaacelerador de la cadena ligera de células B activadas) ${ }^{20,21}$.

Para evitar la inducción de la respuesta inflamatoria y la acción de NET's, $P$. aeruginosa suprime la regulación del gen que codifica para la flagelina cambiando su fenotipo a una cepa mucoide; para ello induce la producción del polisacárido alginato, el que se asocia a daño parenquimatoso $^{18,22}$.

Pseudomonas aeruginosa posee, además, un pili del tipo IV que le confiere la capacidad de adherirse y tener otro tipo de movilidad denominado "swarming". El pili tipo IV contiene a las proteínas PilA, PilB, PilT y PilU. Las últimas dos funcionan como proteínas motoras así como para la transducción de energía en química ATP en mecánica mediante la polimerización y despolimerización de PilA.[23] Este pili IV en asociación con dos lectinas solubles, LecA y LecB presentes en la membrana exterior de la bacteria participan en la adhesión hacia las células del hospedero, induciendo daño y diseminación del patógeno, participando de su supervivencia y la formación de biopelícula ${ }^{17,24}$.

\section{Factores de patogenicidad secretados por la célula bacteriana}

De los factores de virulencia secretados, la bacteria es capaz de producir una cápsula extracelular de alginato, un polímero linear de ácido manurónico y ácido glucurónico y forma parte de la biopelícula secretada por la bacteria como mecanismo de evasión para los anticuerpos y la fagocitosis de las células inmunológicas ${ }^{25}$.

Pseudomonas aeruginosa es capaz de formar dos tipos generales de biopelícula: "plana o inicial" y biopelícula "estructurada o madura". La "plana o inicial" está caracterizada por presentar una confluencia uniforme de bacterias en la superficie. La "estructurada o madura" consiste en agregados celulares inmersos en la matriz de la biopelícula, separadas por canales o espacios ${ }^{26}$.

La formación de la biopelícula plana se inicia cuando la bacteria se adhiere a superficies tisulares, generando la formación de microcolonias, las que crecen por la adhesión de nuevas bacterias y la reproducción de las bacterias ya adheridas.

Una característica importante de la biopelícula es su matriz compuesta por diversos factores secretados, entre los que se encuentran: los polisacáridos Pel (sintetizados por PelA-PelG), Psl (cuyo patrón estructural es helicoidal) y alginato; así como ADN extracelular (eADN) y diversas proteínas como las fimbrias reguladas por los grupos de genes: CupA, CupB y CupC, así como las proteínas de membrana LecA y LecB. (Figura 1) 26,27.

La biopelícula induce la producción de inmunoglobulinas, especialmente IgG contra los componentes de la bacteria, principalmente el alginato. Son estas IgG's específicas las que puede llegar a servir de diagnóstico médico ${ }^{28}$ por otra parte, esta biopelícula también cuenta con la presencia de proteínas en la matriz extracelular con capacidad de unirse a antimicrobianos, lo que impide a los péptidos antimicrobianos alcanzar a los microorganismos. Diversos estudios han confirmado una asociación de bacterias que potencializan la formación de biopelícula dando lugar a co-infecciones crónicas y más resistentes, debido posiblemente a una competición y selección de bacterias resistentes en dicho microambiente ${ }^{24,29,30}$.

Como parte de los factores de virulencia secretados, la bacteria posee el sistema de secreción de toxinas. Psudomonas aeruginosa tiene cinco sistemas de secreción (I, II, III, V y VI) de los siete tipos existentes en las bacterias $^{8}$. El tipo III (SST3) es el principal mecanismo de patogenicidad asociado a la secreción de toxinas que posee la bacteria; por medio de éste secreta toxinas importantes como: Exo A, Exo T, Exo S, Exo U, y ExoY las que pueden llegar a inducir apoptosis ${ }^{31}$.

La traslocación de estas proteínas efectoras de la bacteria ocurre a través de la membrana bacteriana hacia el citoplasma de la célula eucariota por una estructura parecida a una aguja que forma un poro en la membrana eucariota $^{32}$. La exotoxina A (ExoA) es secretada al espacio extracelular y corresponde a una ADP-ribosil-transferasa que inhibe el factor de elogación-2 (EF-2), impidiendo la síntesis de proteínas e induciendo la muerte celular ${ }^{12}$.

La proteína ExoS es una toxina bifuncional con actividad de proteína activadora de GTPasa (GAP) en el extremo carboxilo terminal y actividad de adenosina difosfato ribosil transferasa (ADPRT) en el extremo amino terminal. La GTPasa está asociada a la disrupción del cito-esqueleto de actina lo que propicia la disminución de la internalización de la bacteria por ciertas células, y le sirve a la bacteria como un mecanismo de evasión de la fagocitosis ${ }^{32}$. Se ha demostrado que la proteína ExoS induce apoptosis de células endoteliales, linfocitos $\mathrm{T}$, macrófagos y células epiteliales de las vías aéreas en ratones $^{33}$.

La proteína ExoT tiene funciones muy parecidas a ExoS ya que también es una toxina bifuncional con actividad de proteína activadora de GTPasa y actividad de ADPRT. Además, la proteína ExoT se ha relacionado con retrasos en la cicatrización de heridas lo que aumenta la capacidad oportunista de $P$. aeruginosa $a^{32}$.

La proteína ExoU regula el incremento de CD95 y CD95-ligando en las células infectadas, lo que induce la activación de la vía JNK que inducirá, a su vez, muerte por apoptosis de las células infectadas ${ }^{34}$. La infección por $P$. aeruginosa incrementa de manera importante las 


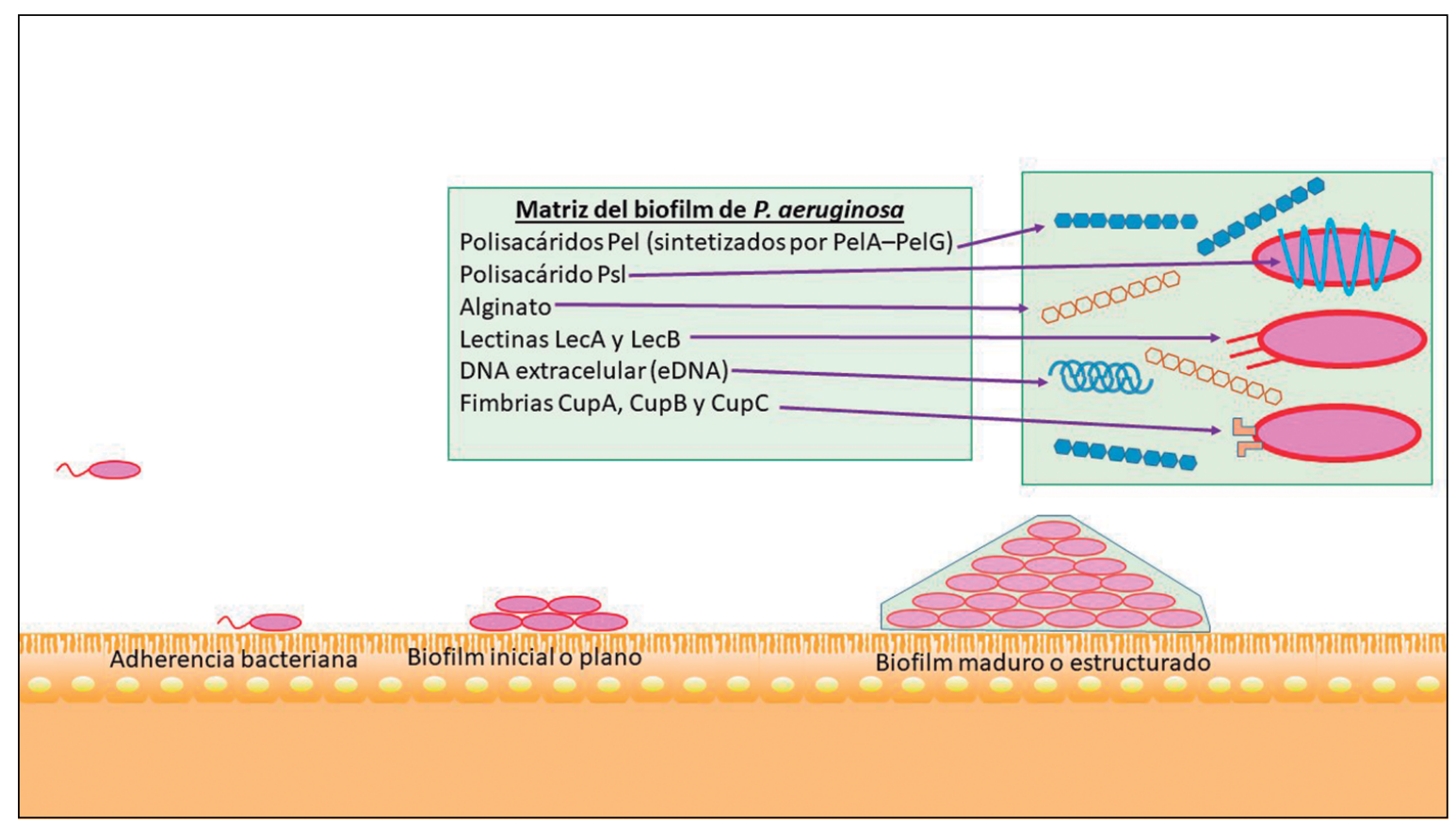

Figura 1. Proceso de formación de la biopelícula en Pseudomonas aeruginosa. La adherencia bacteriana permite la formación de la biopelícula plana. La biopelícula madura se establece cuando el agregado bacteriano genera la matriz mediante la producción de factores secretados. La producción de la matriz se basa en los polisacáridos Pel y Psl, la proteína alginato y lectinas como LecA y LecB.

proteínas JNK y p38 mientras que la proteína ERK se encuentra gradualmente desactivada. Más aún, está el hecho que primero se suprime a la ERK para después activar a p38 y posteriormente a la JNK, lo que contribuiría a la activación de la cascada de señalización para apoptosis ${ }^{31}$.

La proteína ExoY tiene una función adenilato ciclasa y es inyectada directamente en el citosol de la célula del hospedero. La ExoY al unirse con un co-factor, aumenta el cAMP citosólico alterando el citoesqueleto de actina, la inhibición de fagocitosis y el aumento en la permeabilidad endotelial $^{32}$.

Pseudomonas aeruginosa activa la fosfolipasa A2 citosólica en las células infectadas induciendo un aumento de la producción del ácido araquidónico y la activación de la apoptosis ${ }^{34}$.

El sistema de secreción tipo II (SST2) está compuesto de secreciones de multiproteínas codificadas por los operones $x c p$ y $h x c$. Dentro de estas secreciones se encuentra las elastasas. La producción de elastasas LasA y LasB están reguladas por el sistema de "quorum sensing”. La elastasa LasB degrada el colágeno y algunas proteínas ausentes de colágeno, facilita la difusión de la infección destruyendo las barreras físicas e inhibiendo la quimiotaxis de los monocitos, previniendo de esta forma la erradicación inicial del microorganismo en los sitios de heridas por fagocitosis y presentación de antígeno ${ }^{17}$.

El sistema de secreción tipo V (SST5) también cono- cido como sistema auto transportador, es una maquinaria macromolecular presente en varios factores de virulencia que producen lisis de las células eucariotas y que juegan un papel en la producción de biopelícula y adherencia celular. Un ejemplo es la proteína EstA, proteína autotransportadora de esterasas que sirve para la producción de ramnolípidos ${ }^{17}$.

El pigmento denominado como piocianina (un pigmento azul verdoso), uno de los otros factores de virulencia característico de $P$. aeruginosa, es un metabolito secretado que causa disfunción ciliar en el tracto respiratorio, provocando efectos pro-inflamatorios y oxidativos que daña a las células mediante la disrupción de la catalasa y la cadena transportadora de electrones mitocondriales, jugando un efecto protector contra las especies reactivas de oxígeno y especies de nitrógeno producidas por células del sistema inmune ${ }^{17}$.

\section{Quorum sensing}

Otro de los factores de virulencia altamente estudiados en la bacteria es la percepción de quórum o Quorum sensing (QS), un mecanismo basado en la comunicación intercelular que permite la adaptación de una población bacteriana a los cambios microambientales. La adaptación esta mediada por pequeñas moléculas llamadas autoinductores o acil-homoserina lactones (AHL) que difunden a través de las membranas bacteriana ${ }^{21}$.

En el QS, los receptores activados por señales desen- 
cadenan la expresión de genes diana. Estas moléculas de señalización son dependientes de la densidad de bacterias colonizantes coordinando la expresión de genes cuando la comunidad bacteriana alcanza un límite, siendo este el "quorum" 21 . Dos de los principales sistemas del QS son LasIR y RhlIR, además de contar con otro sistema que utiliza señales de tipo quinolona ${ }^{35}$.

Diversas investigaciones sobre el perfil transcripcional han demostrado que el QS es una red regulatoria que puede llegar a controlar directa o indirectamente la expresión de al menos 400 genes $^{26}$. De alguno de los genes que se expresan mediante el QS, son el LasB las que da origen a las elastasas, el operon $r h l A B$ que determina la producción de rhamnolipidos, el operón hcn $A B C$ que produce ácido cianídrico y el gen chic para una quintinasa con actividad hidrolasa $^{36,37}$.

\section{Resistencia antimicrobiana}

Pseudomonas aeruginosa es un primordial microorganismo que causa infecciones nosocomiales en Estados Unidos de América (E.U.A.) (7,1\%) y los países europeos $(8,9 \%)$, siendo uno de los principales patógenos causantes de infecciones predisponentes a ser multi-resistentes debido al entorno intrahospitalario ${ }^{38}$. En México, las infecciones causadas por $P$. aeruginosa van en aumento, así como lo demuestra el sistema de vigilancia epidemiológica hospitalaria del Instituto Mexicano del Seguro Social desde donde se reportó una incidencia de infecciones de $19,9 \%$ en el año 2013 lo que representa un incremento de $6,9 \%$ comparado con los datos del $2011^{39}$.

La alta incidencia de las bacterias multi-resistentes a antimicrobianos ha incentivado la búsqueda sobre los mecanismos de resistencia asociados, con el objetivo de lograr una mejor comprensión y así disminuir la alta morbilidad causada por estos microorganismos. De estas bacterias, $P$. aeruginosa es de las que más frecuentemente desarrolla mecanismos de resistencias. En Asia, aproximadamente $42,8 \%$ de las neumonías nosocomiales por $P$. aeruginosa son multi-resistentes, y $4,9 \%$ son ultra-resistentes ${ }^{40}$. En un estudio de urocultivos realizado durante ocho años por Chavolla y cols., hasta el año 2016, en búsqueda de $P$. aeruginosa, en un hospital de segundo nivel en México, 32\% eran multi-resistentes mientras que cuando se consideraba cualquier tipo de cultivo (hemocultivo, urocultivo etc.), 22\% de las cepas resultó ser multi-resistente. Se concluyó que la multi-resistencia identificada fue en aumento a lo largo de los ocho años de la toma de muestras ${ }^{41}$.

Diversos artículos describen los mecanismos de resistencia de aislados de $P$. aeruginosa en México desde 1986, encontrando los genes IMP-15 y IMP-18, que codifican para la producción de dos metalo- $\beta$-lactamasas y de la producción simultánea de diferentes tipos de BLEE
( $\beta$-lactamasas de espectro extendido). De la misma forma se ha descrito aislados que también cuentan con los genes IMP-15 y VIM-2 que confieren a la bacteria resistencia antibacteriana. Asimismo, en un paciente con fibrosis quística se encontró $P$. aeruginosa productoras de las $\beta$-lactamasas OXA $141^{42-44}$.

\section{Mecanismos de resistencia}

Pseudomonas aeruginosa exhibe muchos mecanismos de resistencia, incluyendo enzimas que modifican a los antimicrobianos como $\beta$-lactamasas y enzimas modificadoras de aminoglucósidos, la adquisición plásmidos que codifican para genes de resistencia, permeabilidad limitada para los antimicrobianos y la posibilidad de generar una bomba dependiente de energía que expulsa al antimicrobiano fuera de la bacteria (Tabla 2$)^{45}$.

Cuatro bombas activas pertenecientes a la resistencia a división por nodulación (RND) han sido descritas en las bacterias gramnegativas que participan activamente en la resistencia antimicrobiana, (MexAB-OprM, MexXY/ OprM, MexCD-OprJ y MexEF-OprN). Pseudomonas aeruginosa utiliza estas bombas para lograr la resistencia contra las diferentes familias de antimicrobianos. MexEF-OprN y MexCD-OprJ confiere resistencia contra fluoroquinolonas ${ }^{45}$, MexAB-OprM, MexEF-OprN and MexCD-OprJ están relacionados a la resistencia contra $\beta$-lactámicos y finalmente, MexXY-OprM, confiere resistencia contra aminoglucósidos ${ }^{45}$.

Se han identificado en $P$. aeruginosa mutaciones en genes cromosomales que le confieren resistencia a penicilinas, cefalosporinas y monobactámicos. Dichas mutaciones se encuentran en los genes involucrados en la síntesis de péptidoglucano ( $\mathrm{ampD}$, dacB, and ampR). Así mismo, las mutaciones específicas en ampC incrementan la resistencia a cefalosporinas antipseudomonas. La resistencia a carbapenémicos como imipenem y meropenem se da mediante la impermeabilidad de la membrana externa gracias a una mutación en la codificación del gen OprD que disminuye la expresión de la proteína en este sitio. Se ha demostrado también, que las mutaciones en los genes de resultan en mutaciones en la $\mathrm{ADN}$ girasa (GyrA7, GyrB) y la topoisomerasa tipo IV (ParC/ParE) inducen la resistencia a fluoroquinolonas. También se ha encontrado que cepas que codifican para el gen $r m t \mathrm{~A}$, que metila la subunidad $16 \mathrm{~s}$ ARNr presentan resistencia a aminoglucósidos ${ }^{46}$.

\section{Infección del tracto urinario causada por Pseudomonas aeruginosa}

Anualmente se reportan más de 8 millones de consultas médicas por infecciones del tracto urinario (ITU), más de 1,5 millones de casos de urgencias médicas y cerca de 300.000 hospitalizaciones, sólo en E.U.A ${ }^{47-50}$. 
Tabla 2. Mecanismos de resistencia por Pseudomonas aeruginosa

\begin{tabular}{|c|c|c|}
\hline Mecanismo & Gen/ Proteína & Resistencia al antimicrobiano \\
\hline Impermeabilidad de la membrana externa & OprD, OprF, OprB & Imipenem, meropenem, quinolonas, aminoglucósidos \\
\hline Bombas de eflujo & MexAB-OprM, MexXY-OprM, MexCD-OprJ, MexEF-OprN & $\beta$-lactámicos, fluoroquinolonas, aminoglucósidos \\
\hline$\beta$-Lactamasas & AmpD, DacB, AmpR, AmpC & $\beta$-lactámicos, penicilinas antipseudomonas \\
\hline Modificación del blanco del antimicrobiano & GyrA7, GyrB, topoisomerasa tipolV (ParC/ParE) rmtA & Fluoroquinolonas, aminoglucósidos \\
\hline Transferencia horizontal & Metalo- $\beta$-lactamasas-clase B & Penicilinas, cefalosporinas, imipenem \\
\hline Cambios en la membrana & $\begin{array}{l}\text { Modificación lípido A } \\
\text { Sobreexpresión de AmpC }\end{array}$ & Penicilinas \\
\hline
\end{tabular}

Diversos son los factores que influyen en la presentación de las ITUs, entre ellos el género, la actividad sexual, enfermedades metabólicas y, en el caso de las infecciones intrahospitalarias, la cateterización del tracto urinario, siendo éste el factor más común que predispone a la ITU ${ }^{51-54}$.

Existen diversos agentes etiológicos responsables de ITUs asociadas a catéter, pero dentro de las infecciones de origen bacteriano las principales son Escherichia coli, Proteus mirabilis, $P$. aeruginosa, Klebsiella pneumoniae y Streptococcus faecalis. Las infecciones por Pseudomonas ocupan el tercer lugar de ITUs adquiridas en el ámbito intrahospitalario y asociadas a catéter ${ }^{55-57}$.
Durante la patogenia de la infección urinaria convergen diversos mecanismos como los factores de patogenicidad de cada bacteria.

Existe evidencia de la participación de ciertos factores microambientales en el tracto urinario asociados a la infección por $P$. aeruginosa. Dichos factores microambientales están dados por la estructura e integridad celular y tisular, moléculas expresadas y composición química, osmolaridad y $\mathrm{pH}$ de la orina, los que dependen de la edad, dieta y condición fisiológica o grado de enfermedad del paciente (Figura 2).

Dentro de los factores microambientales en el tracto urinario involucrados en la fisiopatología de la enferme-

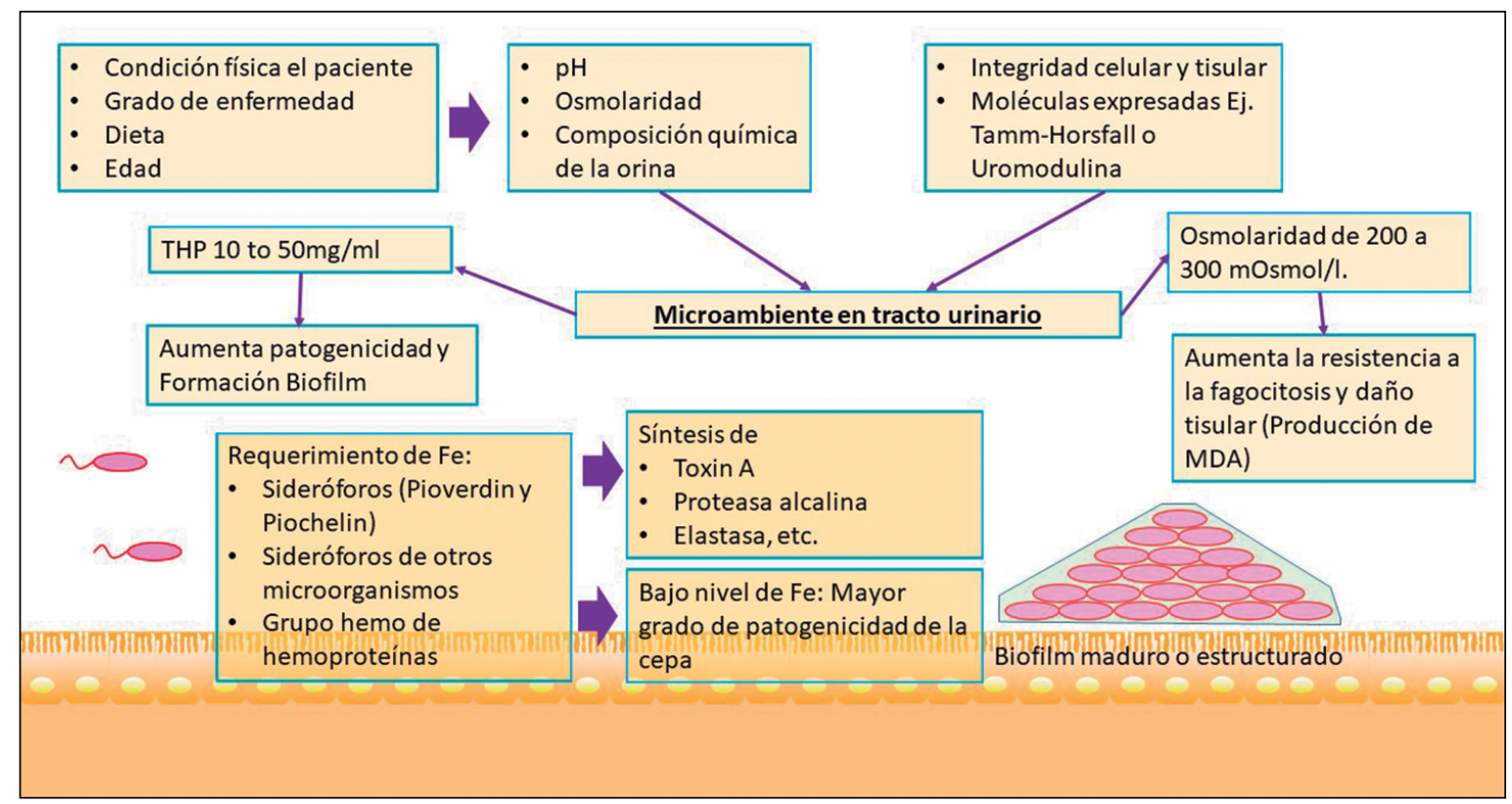

Figura 2. Factores micro-ambientales que permiten la colonización por Pseudomonas aeruginosa. La condición del paciente como la dieta o la edad, pueden alterar la osmolaridad y composición química de la orina modificando el microambiente del tracto urinario. La diferente integridad celular, así como la producción de la proteína Tamm-Horsfall por el riñón pueden cambiar el microambiente urinario favoreciendo una mayor patogenicidad de $P$. aeruginosa. La bacteria consigue hierro a través de pioverdina y/o piochelina, también mediante las hemoproteínas y lo usa para la síntesis de toxina A, proteasa alcalina y otros factores de patogenicidad. 
dad urinaria se incluyen a la osmolaridad de la orina, $\mathrm{pH}$ de la orina, la proteína Tamm-Horsfall (PTH) o uromodulina (un inhibidor de la cristalización del calcio en la orina), los iones de hierro, entre otros ${ }^{58}$.

Pseudomonas aeruginosa requiere de hierro para sobrevivir y crecer, así como para producir diversos factores de patogenicidad como la Exo A, proteasa alcalina y elastasa entre otros ${ }^{59-62}$. Para obtener hierro de su entorno secreta dos sideróforos conocidos como pioverdina y piochelina (con alta y baja afinidad por el hierro, respectivamente); también puede llegar a aprovechar el sideróforo secretado de otros microorganismos. Adicionalmente, esta bacteria puede obtener hierro a partir del grupo hemo de las hemoproteínas ${ }^{63}$.

Mittal y cols. en el año 2008, demostraron que los cultivos $P$. aeruginosa mantenidos en un medio pobre en hierro son más virulentos en comparación con los cultivados en un medio rico en hierro. Lo anterior sugiere que el nivel bajo de hierro en el cultivo induce la sobreproducción de otros factores de patogenicidad a un mayor nivel, en comparación al cultivo con niveles "confortablemente" altos de hierro aludiendo esto a un mecanismo de sobrevivencia bacteriana ${ }^{64}$.

La osmolaridad de la orina es variable y depende de diversos factores como la edad, sexo, estado fisiológico del paciente, entre otros. Se consideran valores normales de la osmolaridad de la orina de 50 a 1.400 miliosmoles por kilogramo $(\mathrm{mOsm} / \mathrm{kg})$. La hipertonicidad y bajo $\mathrm{pH}$ de la orina ejercen un efecto inhibitorio para el crecimiento de la mayoría de microorganismos ${ }^{64,65}$. Pseudomonas aeruginosa, como otros patógenos de vías urinarias, debe poseer la capacidad de adaptarse, sobrevivir y crecer bajo estas condiciones de variabilidad de osmolaridad de la orina. Especialmente $P$. aeruginosa posee una excepcional capacidad de adaptación a los microambientes. Mittal y cols., demostraron en el año 2009 que condiciones de osmolaridad de 200 a $300 \mathrm{mOsmol} / \mathrm{l}$. incrementaban la patogenicidad de $P$. aeruginosa, aumentaban la resistencia a la fagocitosis y se correlacionaba con la producción de malondialdehido (MDA), siendo éste un marcador de daño tisular (renal y de vejiga urinaria) ${ }^{66}$.

Cetiner y cols., demostraron en el año 2017 que $P$. aeruginosa, en comparación a otras bacterias, posee, por una parte, una menor permeabilidad al agua $y$, por otro lado, una mayor velocidad de liberación de osmolitos ante diluciones con alta osmolaridad. Para ello, P. aeruginosa emplea canales a manera de válvulas para eliminar los osmolitos hacia el exterior de la bacteria como método para sobrevivir en el ambiente hipertónico de la orina ${ }^{67}$.

La THP es una glicoproteína sintetizada en riñón y la proteína más abundante en vías urinarias. Los valores normales de excreción van de 50-100 miligramos por día. Mittal y cols., demostraron en el año 2006 que concentraciones de 10 to $50 \mathrm{mg} / \mathrm{ml}$ de THP inducían, de forma dosis-dependiente, la producción de factores de patogenicidad. Este incremento gradual de la virulencia decrecía después de los $50 \mathrm{mg} / \mathrm{ml}$. Por otra parte, se ha demostrado que a concentraciones de $50 \mathrm{mg} / \mathrm{ml}$, la THP contribuye a la formación de biopelícula permitiendo a $P$. aeruginosa sobrevivir y escapar de la fagocitosis ${ }^{68}$.

Existen factores, como la pérdida de la integridad tisular, que se han reconocido como facilitadores de la formación de biopelícula; lo anterior puede ocurrir al introducir catéteres en vía urinaria ${ }^{66}$.

\section{Posibles alternativas de tratamiento}

La era de los antimicrobianos está cada vez más en peligro de desaparecer debido a la aparición de cepas bacterianas multi-resistentes. Lo que obliga a tener una cultura médica de no prescribir antimicrobianos innecesarios y a buscar nuevas alternativas para hacer frente a la resistencia bacteriana. El tratamiento de infecciones por $P$. aeruginosa resistente debe incluir antimicrobianos, seleccionados según el antibiograma. La producción de metalo- $\beta$-lactamasas, que inactivan muchos antimicrobianos $\beta$-lactámicos (excepto aztreonam), supone un gran problema en el manejo de las infecciones por este microorganismo ${ }^{69}$. En un estudio multicéntrico en España se probó la susceptibilidad y resistencia de los cultivos aislados de $P$. aeruginosa encontrando que $24 \%$ de las cepas eran resistentes a uno o dos antimicrobianos y $33 \%$ aproximadamente eran multi-resistentes. De la misma forma, arrojan datos sobre el porcentaje de resistencia a diversos antimicrobianos: $38,4 \%$ eran resistentes a cefepime, $23,7 \%$ a ceftazidima, $32,6 \%$ a aztreonam, 32,1 y $22,6 \%$ resistentes a imipenem y meropenem, respectivamente, $28,4 \%$ a ciprofloxacina y $22,1 \%$ a gentamicina, siendo estos datos muy altos y alarmantes pues en este listado se encuentran los principales antimicrobianos para el manejo de las infecciones causadas por $P$. aeruginos $a^{70}$. No obstante, también se menciona que sólo $3,2 \%$ eran resistentes a colistín, uno de los pocos antimicrobianos que se utiliza en caso de multi-resistencia bacteriana y de difícil control.

Como tratamiento alternativo contra bacterias multiresistentes, como es $P$. aeruginosa, se proponen nuevas moléculas con actividad antibacteriana. Las bacteriocinas han demostrado potencia (in vitro e in vivo) en la inhibición bacteriana; además poseen baja toxicidad. Otras de sus ventajas son la disponibilidad de péptidos de espectro amplio y estrecho y la posibilidad de producción in situ por los probióticos. Existen dos tipos de bacteriocinas: las de clase I y las de clase II. Las bacteriocinas clase I son péptidos que experimentan modificaciones post-traduccionales significativas; contrariamente, las bacteriocinas clase II son péptidos no sujetos a dichos cambios ${ }^{71,72}$.

Los tiopéptidos son también predominantemente activos 
contra patógenos grampositivos. Los tiopéptidos presentan una actividad in vitro altamente potente, pero su desarrollo comercial se ha visto obstaculizado por su escasa solubilidad. También hay muchos ejemplos de bacteriocinas no modificadas de clase II con potente actividad antimicrobiana contra especies grampositivas. Existen muchos ejemplos de bacteriocinas con actividad sustancial contra bacterias gramnegativas in vitro; la opinión generalmente sostenida es que las bacteriocinas presentan menos potencial como quimioterapéuticos con organismos gramnegativos ${ }^{71}$. Las bacteriocinas producidas por bacterias gramnegativas, normalmente denominadas microcinas, suelen mostrar el mayor potencial. A menudo muestran un espectro estrecho de actividad ya que ha habido pocos estudios en los que se hayan evaluado actividades específicas ${ }^{71}$.

La eficacia de las bacteriocinas individuales podría mejorarse adicionalmente mediante la combinación con otros antimicrobianos o sustancias activas de membrana. Aunque ha habido pocos estudios en esta área, la nisina mostró actividad sinergística con los antimicrobianos polimixina E y claritromicina contra $P$. aeruginosa. Claramente, las bacteriocinas siguen en investigación, pero pueden ser muy útiles en un futuro para remplazar a los antimicrobianos, en particular contra organismos multi-resistentes ${ }^{71}$.

Se ha propuesto un tratamiento, en vías de investigación, sobre el uso de bacteriófagos, los que producen alginasa, una enzima que despolimeriza el alginato de la cápsula formada por la bacteria en la matriz de la biopelícula; también cuentan con otras enzimas que pueden degradar el exo-polisacárido en las biopelículas ${ }^{72}$.

Una de las terapias contra las infecciones por Pseudomonas, es el uso de probióticos. Se ha encontrado que las cepas de lactobacilos son las que mejor actividad tienen en altas concentraciones de sales, pero con baja tolerancia de $\mathrm{pH}$. Las cepas de Lactobacillus L1 y L2 demuestran una inhibición significante (80-100\%) contra las cepas de Pseudomonas inhibiendo el crecimiento al momento de co-cultivarlas; además de esto, hay una reducción de la biopelícula de 0 a 64\% comparado con las cepas de Pseudomonas cultivadas de manera aislada ${ }^{73}$. No obstante, aunque esto es un dato promisorio, se deben de seguir haciendo investigaciones in vivo para poder determinar su eficacia en infecciones por $P$. aeruginosa.

\section{Conclusiones}

El surgimiento y rápida aparición de cepas bacterianas multi-resistentes a nivel mundial han hecho que la ciencia se replantee el uso adecuado e inadecuado de los antimicrobianos, así como la investigación en nuevas alternativas terapéuticas.

El conocimiento de los factores de patogenicidad de estas bacterias multi-resistentes, así como de los mecanismos moleculares que participan de la fisiopatología de las infecciones que producen, resultan de suma utilidad para entender y tratar estas infecciones, más ahora que enfrentamos la actual problemática de multi-resistencia.

Dentro de las infecciones importantes producidas por $P$. aeruginosa, se encuentran las infecciones urinarias y otras nosocomiales. Para entender y avanzar en nuevas rutas de tratamiento, las investigaciones recientes se enfocan a comprender los mecanismos de patogenicidad del microorganismo en el contexto del microambiente que le rodea y los factores del hospedero con los que se encuentra la bacteria.

\section{Resumen}

Dentro de las infecciones nosocomiales más frecuentes asociadas a bacterias multi-resistentes y de peor pronóstico, se encuentran las producidas por Pseudomonas aeruginosa. Esta bacteria posee una alta capacidad de adaptación a condiciones adversas como por ejemplo el pH y la osmolaridad de la orina. Pseudomonas aeruginosa es uno de los principales patógenos implicados en infecciones nosocomiales y de pacientes inmunosuprimidos. Esta bacteria se considera un agente infeccioso oportunista que posee diversos mecanismos de patogenicidad, así como de resistencia a antimicrobianos, lo que contribuye a la dificultad en el tratamiento de estas infecciones. En la presente revisión bibliográfica se analizan la taxonomía, los mecanismos de patogenicidad y genes de resistencia de $P$. aeruginosa. Así también, se abordan los factores microambientales de la infección urinaria producida por esta bacteria, haciendo un acercamiento al entendimiento de las bases fisiopatológicas de esta infección.

\section{Referencias bibliográficas}

1.- Palleroni NJ. The Pseudomonas story. Environ. Microbiol. 2010; 12 (6): 1377-83. doi: $10.1111 / \mathrm{j} .1462-2920.2009 .02041 . x$

2.- Hugh R and Leifson E. The proposed neotype strains of Pseudomonas aeruginosa (Schroeter 1872) Migula 1900. Int Bull Bacteriol Nomencl Taxon., 1964; 14 (2): 69-84. doi: 10.1601/ nm.2553.

3. Pollack M. The virulence of Pseudomonas aeruginosa. Rev Infect Dis. 1984; 6. Suppl 3: S617-2. PMID: 6443764.

4.- Peix A, Ramírez-Bahena MH, Velázquez E. Historical evolution and current status of the taxonomy of genus Pseudomonas. Infect. Genet. Evol. 2009; 9(6): 1132-47. doi: 10.1016/j.meegid.2009.08.001.
5.- Stanier RY, Palleroni NJ, Doudoroff M. The aerobic pseudomonads a taxonomic study. J. Gen. Microbiol. 1966; 43 (2): 159-271. DOI: $10.1099 / 00221287-43-2-159$.

6.- Palleroni NJ, Kunisawa R, Contopoulou R, Doudoroff M. Nucleic acid homologies in the Genus Pseudomonas. Int. J. Syst. Bacteriol. 1973; 23(4): 333-9.

7.- Ferguson D. A study of clinical strains of 
Pseudomonas aeruginosa and the investigation of antibiotic resistance mechanisms in the multidrug resistant strain PA13. PhD thesis, Dublin City Univ., 2007. http://doras.dcu. ie/105/1/ferguson_damien_2008.pdf

8.- Mesquita CS, Soares-Castro P, Santos PM. Pseudomonas aeruginosa: phenotypic flexibility and antimicrobial resistance. In: Microbial pathogens and strategies for combating them: science, technology and education. A. Méndez-Vilas, Ed.

9.- W. B. Whitman et al., Eds., Bergey's Manual of Systematics of Archaea and Bacteria. Chichester, UK: John Wiley \& Sons, Ltd, 2015.

10.- Vander Wauven C, Piérard A, Kley-Raymann M, Haas D. Pseudomonas aeruginosa mutants affected in anaerobic growth on arginine: evidence for a four-gene cluster encoding the arginine deiminase pathway. J. Bacteriol. 1984; 160 (3): 928-34. PMCID: PMC215798.

11.- Yordanov D, Strateva T. Pseudomonas aeruginosa - a phenomenon of bacterial resistance. J. Med. Microbiol. 2009; 58(9): 1133-48. doi: 10.1099/jmm.0.009142-0.

12.- Driscoll JA, Brody SL, Kollef MH. The epidemiology, pathogenesis and treatment of Pseudomonas aeruginosa infections. Drugs 2007; 67 (3): 351-68. DOI: 10.2165/00003495200767030-00003.

[13.- Gellatly SL, Hancock RE. Pseudomonas aeruginosa: new insights into pathogenesis and host defenses. Pathog. Dis. 2013; 67(3): 15973. doi: 10.1111/2049-632X.12033.

14.- Pereira SG, Rosa AC, Cardoso O. Virulence factors as predictive tools for drug resistance in Pseudomonas aeruginosa. Virulence 2015; 6 (7): 679-83. doi: 10.1080/21505594.2015.1048958.

15.- J. Elliott J, Simoska O, Karasik S, Shear JB, Stevenson KJ. Transparent carbon ultramicroelectrode arrays for the electrochemical detection of a bacterial warfare toxin, pyocyanin. Anal. Chem. 2017; 89 (12): 6285-9. doi: 10.1021/acs.analchem.7b00876.

16.- Arora SK, Ritchings BW, Almira EC, Lory S, Ramphal R. The Pseudomonas aeruginosa flagellar cap protein, FliD, is responsible for mucin adhesion. Infect. Immun. 1998; 66 (3): 1000-7. PMCID: PMC108008.

17.- Al-Wrafy F, Brzozowska E, Górska S, Gamian A, Al-Wrafy FA. Pathogenic factors of Pseudomonas aeruginosa - the role of biofilm in pathogenicity and as a target for phage therapy. Postep. Hig Med Dosw 2016; 70(70): 78-91. 10.5604/01.3001.0010.3792.

18.- Rada B. Neutrophil extracellular trap release driven by bacterial motility: Relevance to cystic fibrosis lung disease. Commun. Integr. Biol. 2017; 10(2): e1296610. doi: 10.1080/19420889.2017.1296610.

19.- Arnason JW., Murphy JC, Kooi C, Wiehler $\mathrm{S}$, Traves SL, Shelfoon C, et al. Human $\beta$-defensin-2 production upon viral and bacterial co-infection is attenuated in COPD. PLoS One 2017; 12(5):,e0175963. doi: 10.1371/journal.pone. 0175963 .

20.- Cendra MDM, Christodoulides M, Hossain P. Signaling mediated by toll-like receptor 5 sensing of Pseudomonas aeruginosa flagellin influences IL-1 $\beta$ and IL-18 production by primary fibroblasts derived from the human cornea. Front. Cell. Infect. Microbiol. 2017; 7: 130. doi: $10.3389 /$ fcimb. 2017.00130

21.- Kipnis E, Sawa T, Wiener-Kronish J. Targeting mechanisms of Pseudomonas aeruginosa pathogenesis. Médecine Mal. Infect. 2006; 36 (2): 78-91. DOI: 10.1016/j. medmal.2005.10.007.

22.- Chotirmall SH, Smith SG, Gunaratnam C, Cosgrove S, Dimitrov BD, O’Neill SJ, et al. Effect of estrogen on Pseudomonas mucoidy and exacerbations in cystic fibrosis. N Engl J Med 2012; 366 (21): 1978-86. doi: 10.1056/ NEJMoa1106126.

23.- Yang J, Toyofuku M, Sakai R, Nomura N. Type IV pili mechanochemically regulate virulence factors in Pseudomonas aeruginosa. Environ. Microbiol. Rep. 2017; 9(3): 239-49 ttps:// dx.doi.org/10.1073\%2Fpnas.1502025112.

24.- Persat A, Heydorn A, Ragas P, Lambertsen L, Aaes-Jørgensen A, Molin S, et al. Biofilm formation by Pseudomonas aeruginosa wild type, flagella and type IV pili mutants. Proc Natl Acad Sci USA 2015; 112(24): 7563-8. PMID: 12791135.

25.- Faezi S, Bahrmand AR, Mahdavi M, Siadat SD, Sardari S, Nikokar I, et al. Preparation of Pseudomonas aeruginosa alginate-flagellin immunoconjugate. Biologicals 2017; 47: 11-7. DOI: 10.1016/j.biologicals.2017.04.001.

26.- Kirisits MJ, Parsek MR. Does Pseudomonas aeruginosa use intercellular signalling to build biofilm communities? Cell. Microbiol. 2006; 8 (12): 1841-9. DOI: 10.1111/j.14625822.2006.00817.x

27.- Hauser AR, Ozer EA. Pseudomonas aeruginosa. Nat Rev Microbiol 2011; 9 (3): https://www.facebook.com/notes/ nature-reviews/poster-pseudomonasaeruginosa/362360707120676

28.- Høiby N, Bjarnsholt T, Moser C, Jensen PØ, Kolpen M, Qvist T, et al. Diagnosis of biofilm infections in cystic fibrosis patients. APMIS 2017; 125 (4): 339-43. doi: 10.1111/apm.12689.

29.- Jorge P, Grzywacz D, Kamysz W, Lourenço A, Pereira M O. Searching for new strategies against biofilm infections: Colistin-AMP combinations against $P$ seudomonas aeruginosa and Staphylococcus aureus single- and doublespecies biofilms. PLoS One 2017; 12 (3): e0174654. doi: 10.1371/journal.pone.0174654.

30.- Scoffield J A, Duan D, Zhu F, Wu H. A commensal streptococcus hijacks a Pseudomonas aeruginosa exopolysaccharide to promote biofilm formation. PLOS Pathog 2017; 13(4) e1006300. doi: 10.1371/journal. ppat. 1006300 .

31.- Woong Chung J, Zheng-Hao Piao, Suk Ran Yoon, Mi Sun Kim, Mira Jeong, Suk Hyung Lee, et al. Pseudomonas aeruginosa eliminates natural killer cells via phagocytosis-induced apoptosis. PLoS Pathog. 2009; 5(8):e1000561. https://doi.org/10.1371/journal.ppat.1000561.

32.- Hauser AR. The type III secretion system of Pseudomonas aeruginosa: infection by injection. Nat Rev Microbiol 2009; 7 (9): 65465. doi: 10.1038/nrmicro2199.

33.- Jia J, Wang Y, Zhou L, Jin S. Expression of Pseudomonas aeruginosa toxin ExoS effectively induces apoptosis in host cells. Infect. Immun. 2006; 74 (12): 6557-70. doi: 10.1128/IAI.00591-06.

34.- Jendrossek V, Grassmé H, Mueller I, Lang F, Gulbins E. Pseudomonas aeruginosa-induced apoptosis involves mitochondria and stressactivated protein kinases. Infect. Immun. 2001; 69(4): 2675-83. DOI: 10.1128/IAI.69.4.26752683.2001

35.- Toyofuku M, Nomura N, Kuno E, Tashiro Y, Nakajima T, Uchiyama H. Influence of the Pseudomonas quinolone signal on denitrification in Pseudomonas aeruginosa. J Bacteriol 2008; 190 (24): 7947-56. doi: 10.1128/JB.00968-08.

36.- Gökalsın B, Aksoydan B, Erman B, Sesal NC. Reducing virulence and biofilm of Pseudomonas aeruginosa by potential quorum sensing inhibitor carotenoid: zeaxanthin. Microb Ecol 2017; 74 (2): 466-73. doi: 10.1007/s00248-017-0949-3.

37.- Gupta RK, Harjai K, Chhibber S. Rhl quorum sensing affects the virulence potential of Pseudomonas aeruginosa in an experimental urinary tract infection. Antonie Van Leeuwenhoek 2016; 109(12): 1535-44. DOI: $10.1007 / \mathrm{s} 10482-016-0755-9$.

38.- Olaechea PM, Insausti J, Blanco A, Luque P Epidemiología e impacto de las infecciones nosocomiales. Med. Intensiva 2010; 34 (4): 256-67. DOI: 10.1016/j.medin.2009.11.013.

39.- Arias-Flores CR, Rosado-Quiab U, Vargas-Valerio A, Grajales-Muñiz. Los microorganismos causantes de infecciones nosocomiales en el Instituto Mexicano del Seguro Social. Rev. Med. Inst. Mex. Seguro Soc 2016; 54 (1): 20-4. http://www. medigraphic.com/pdfs/imss/im-2016/im161d. pdf.

40.- Ding C, Yang Z, Wang J, Liu X, Cao Y, Pan Y, et al. Prevalence of Pseudomonas aeruginosa and antimicrobial-resistant Pseudomonas aeruginosa in patients with pneumonia in mainland China: a systematic review and metaanalysis. Int J Infect Dis 2016; 49: 119-28. doi: 10.1016/j.ijid.2016.06.014.

41.- Chavolla-Canal A J, González-Mercado M 
G, Ruiz-Larios O A. Prevalencia de bacterias aisladas con resistencia antibiótica extendida en los cultivos de orina durante 8 años en un hospital de segundo nivel en México. Rev Mex Urol 2016; 76 (4): 213-7. https://doi. org/10.1016/j.uromx.2016.04.003.

42.- Rodríguez-Noriega E., León-Garnica G, Petersen-Morfín S, Pérez-Gómez HR, González-Díaz E, Morfín-Otero R. La evolución de la resistencia bacteriana en México, 1973-2013. Biomédica 2013; 34(0): 181-90. doi: http://dx.doi.org/10.7705/ biomedica.v34i0.2142.

43.- Sánchez-Martinez G, Garza-Ramos UJ, Reyna-Flores FL, Gaytán-Martínez J, LorenzoBautista IG, Silva-Sanchez J. In169, A new class 1 integron that encoded blaimp-18 in a multidrug-resistant Pseudomonas aeruginosa isolate from Mexico. Arch. Med. Res., vol. 2010; 41(4): 235-9. doi: 10.1016/j. arcmed.2010.05.006.

44.- Garza-Ramos U, Morfin-Otero R, Sader HS, Jones RN, Hernández E, Rodriguez-Noriega E, et al. Metallo-beta-lactamase gene bla(IMP-15) in a class 1 integron, In95, from Pseudomonas aeruginosa clinical isolates from a hospital in Mexico. Antimicrob. Agents Chemother.2008; 52 (8): 2943-6. doi: 10.1128/AAC.00679-07.

45.- Llanes C, Köhler T, Patry I, Dehecq B, van Delden C, Plésiat P. Role of the MexEFOprN efflux system in low-level resistance of Pseudomonas aeruginosa to ciprofloxacin. Antimicrob. Agents Chemother 2011; 55 (12): 5676-84. doi: 10.1128/AAC.00101-11.

46.- Juan C, Peña C, Oliver A. Host and pathogen biomarkers for severe Pseudomonas aeruginosa infections. J. Infect. Dis. 2017: 215(Suppl 1): S44-S51. doi: 10.1093/infdis/jiw299.

47.- Chang SL, Shortliffe LD. Pediatric urinary tract infections. Pediatr. Clin. North Am 2006; 53 (3): 379-400. DOI: 10.1016/j.pcl.2006.02.011.

48.- Kucheria R, Dasgupta P, Sacks SH, Khan MS, Sheerin NS. Urinary tract infections: new insights into a common problem. Postgrad Med J 2005; 81 (952): 83-6. DOI: 10.1136/ pgmj.2004.023036.

49.- Foxman B. Epidemiology of urinary tract infections: incidence, morbidity, and economic costs. Am J Med 2002; 113 (1): 5-13. PMID: 12113866.

50.- Desforges JF, Stamm WE, Hooton TM. Management of urinary tract infections in adults. N. Engl. J. Med. 1993; 329(18): 132834. DOI: 10.1056/NEJM199310283291808.

51.- Bass PF, Jarvis JAW, Mitchell CK. Urinary tract infections. Prim Care Clin Off Pract 2003; 30 (1): 41-61. PMID: 12838910.

52.- Reid G. Current scientific understanding of urinary tract infections in women: an overview. World J. Urol. 1999; 17(6): 336-8. https://doi. org/10.1007/s003450050157.

53.- Saint S, Chenoweth CE. Biofilms and catheterassociated urinary tract infections. Infect. Dis. Clin North Am 2003; 17 (2): 411-32. PMID: 12848477

54.- Shaw GM, Iovannisci DM, Yang W, Finnell RH, Carmichael SL, Cheng S, et al. Endothelial nitric oxide synthase (NOS3) genetic variants, maternal smoking, vitamin use, and risk of human orofacial clefts. Am J Epidemiol 2005; 162 (12): 1207-14. DOI: 10.1093/aje/kwi336.

55.- Chang, SC, Chen YC, Hsu LY. Epidemiologic study of pathogens causing nosocomial infections. J. Formos. Med. Assoc. 1990; 89 (11): 1023-30, 1015. PMID: 1982123.

56.- Fluit AC, Schmitz FJ, Verhoef J and the E. S. P. Group. Frequency of isolation of pathogens from bloodstream, nosocomial pneumonia, skin and soft tissue, and urinary tract infections occurring in European patients. Eur. J. Clin. Microbiol. Infect. Dis. 2001; 20(3): 0188-91. PMID: 11347669.

57.- Hooton TM. Recurrent urinary tract infection in women. Int. J. Antimicrob. Agents, 2001; 17(4): 259-68. PMID: 11295405

58.- Newman JW, Floyd RV, Fothergill LJ. The contribution of Pseudomonas aeruginosa virulence factors and host factors in the establishment of urinary tract infections. FEMS Microbiol. Lett. 2017; 364 (15). doi: 10.1093/ femsle/fnx124.

59.- Lamont IL, Beare PA, Ochsner U, Vasil AI, Vasil ML. Siderophore-mediated signaling regulates virulence factor production in Pseudomonas aeruginosa. Proc. Natl. Acad. Sci. U. S. A. 2002; 99(10): 7072-7. doi: 10.1073/pnas.092016999.

60.- Rédly GA, Poole K. Pyoverdine-mediated regulation of FpvA synthesis in Pseudomonas aeruginosa: involvement of a probable extracytoplasmic-function sigma factor, FpvI. J. Bacteriol. 2003; 185(4): 1261-5. doi: 10.1128/ JB.185.4.1261-1265.2003.

61.- Visca P, Imperi F, Lamont IL. Pyoverdine siderophores: from biogenesis to biosignificance. Trends Microbiol. 2007; 15(1): 22-30. DOI: 10.1016/j.tim.2006.11.004.

62.- Cornelis P. Iron uptake and metabolism in pseudomonads. Appl. Microbiol. Biotechnol. 2010; 86(6): 1637-45. doi: 10.1007/s00253010-2550-2.

63.- Cornelis P, Dingemans J. Pseudomonas aeruginosa adapts its iron uptake strategies in function of the type of infections. Front. Cell. Infect. Microbiol. 2013; 3: 75. doi: 10.3389/ fcimb.2013.00075.

64.- Mittal R, Sharma S, Chhibber S, Harjai K. Iron dictates the virulence of Pseudomonas aeruginosa in urinary tract infections. J. Biomed. Sci. 2008; 15(6): 731-41. doi: 10.1007/s11373-008-9274-7.

65.- Chambers ST, Lever M. Betaines and urinary tract infections. Nephron 1996; 74(1): 1-10. DOI: $10.1159 / 000189274$.

66.- Mittal R, Sharma S, Chhibber S, Harjai $\mathrm{K}$. Effect of osmolarity on virulence of uropathogenic Pseudomonas aeruginosa. Am. J. Biomed. Sci 2009; 1(1): 12-26. doi: 10.5099/ aj090100012.

67.- Çetiner U, Rowe I, Schams A, Mayhew C, Rubin D, Anishkin A, et al. Tension-activated channels in the mechanism of osmotic fitness in Pseudomonas aeruginosa. J. Gen. Physiol. 2017; 149(5): 595-609. doi: 10.1085/ jgp.201611699.

68.- Mittal R, Sharma S, Chhibber S, Harjai K. Alteration in virulence characteristics of biofilm cells of Pseudomonas aeruginosa in presence of Tamm-Horsfall protein. World J Microbiol Biotechnol 2006; 22 (9): 915-9. https://doi.org/10.1007/s11274-006-9135-3.

69.- Fariñas MC, Martínez-Martínez L. Infecciones causadas por bacterias gramnegativas multirresistentes: enterobacterias, Pseudomonas aeruginosa, Acinetobacter baumannii y otros bacilos gramnegativos no fermentadores. Enferm Infecc Microbiol Clin 2013; 31 (6): 402-9. https://doi.org/10.1016/j. eimc.2013.03.016.

70.- Cabot G, Ocampo-Sosa AA, Tubau F, Macia MD, Rodríguez C, Moya B, et al. Overexpression of AmpC and efflux pumps in Pseudomonas aeruginosa isolates from bloodstream infections: prevalence and impact on resistance in a Spanish multicenter study. Antimicrob. Agents Chemother. 2011; 55 (5): 1906-11. doi: 10.1128/AAC.01645-10.

71.- Cotter P D, Ross R P, Hill C. Bacteriocins a viable alternative to antibiotics? Nat Rev Microbiol. 2013; 11(2): 95-105. doi: 10.1038/ nrmicro2937.

72.- Hughes D, Karlén A. Discovery and preclinical development of new antibiotics. Ups. J. Med. Sci. 2014; 119(2): 162-9. doi: 10.3109/03009734.2014.896437.

73.- Shokri D, Khorasgani MR, Mohkam M, Fatemi SM, Ghasemi Y, Taheri-Kafrani A. The inhibition effect of Lactobacilli against growth and biofilm formation of Pseudomonas aeruginosa. Probiotics Antimicrob. Proteins 2018; 10(1) 34-42. doi: 10.1007/s12602-0179267-9. 